\title{
Laryngeal Cancer pN1 TNM Finding v8
}

National Cancer Institute

\section{Source}

National Cancer Institute. Laryngeal Cancer pN1 TNM Finding v8. NCI Thesaurus. Code C133142.

Laryngeal cancer with metastasis in a single ipsilateral lymph node, $3 \mathrm{~cm}$ or less in greatest dimension and ENE(-). (from AJCC 8th Ed.) 